\title{
Nitrogênio e água como fatores de produtividade do trigo no cerrado
}

\author{
Maria da G. Trindade' ${ }^{1}$ Luís F. Stone ${ }^{2}$, Alexandre B Heinemann², Abelardo D. Cánovas ${ }^{2}$ \& José A. A. Moreira ${ }^{2}$
}

\begin{abstract}
RESUMO
Visando avaliar os efeitos do manejo da irrigação e de doses de nitrogênio na produtividade de duas cultivares de trigo e seus componentes, conduziram-se dois experimentos na Embrapa Arroz e Feijão, em Santo Antônio de Goiás, GO, em plantio direto, na palhada da cultura da soja em um dos quais o reinício da irrigação se dava na tensão matricial de $40 \mathrm{kPa}$ e, no outro, na de $60 \mathrm{kPa}$. O delineamento experimental em ambos os experimentos foi o de blocos ao acaso, com parcelas subdivididas e quatro repetições. Nas parcelas foram estabelecidas cinco doses de nitrogênio em cobertura: 0, 50, 100, 150 e $200 \mathrm{~kg} \mathrm{ha}^{-1}$ e, nas subparcelas, as cultivares EMBRAPA 22 e EMBRAPA 42. A tensão matricial de $60 \mathrm{kPa}$ foi mais adequada para o manejo da irrigação no trigo, de vez que não afetou sua produtividade nem a qualidade mas utilizou menor lâmina total de água. A dose de nitrogênio em cobertura que proporcionou a máxima eficiência técnica, foi de $73 \mathrm{~kg} \mathrm{ha}^{-1}$. O teor de proteína bruta aumentou com o incremento de nitrogênio, enquanto o incremento da freqüência de irrigação e de nitrogênio diminuiu o peso hectolítrico.
\end{abstract}

Palavras-chave: Triticum aestivum, plantio direto, adubação nitrogenada, tensão da água do solo

\section{Nitrogen and water as factors of wheat productivity in cerrado region}

\begin{abstract}
Two experiments were carried out at Embrapa Rice and Beans, located at the municipality of Santo Antônio de Goiás, Goiás state, Brazil, under no-tillage in the soybean straw, to evaluate the effects of irrigation management and nitrogen doses on the grain yield and its components of two wheat cultivars. In the first experiment, the irrigation was started at soil-water tension of $40 \mathrm{kPa}$, and in the second one, at soil-water tension of $60 \mathrm{kPa}$. For both experiments, a randomized block design with subdivided plots, with four replications, was used. In the plots were established five doses of nitrogen $\left(0,50,100,150\right.$, and $\left.200 \mathrm{~kg} \mathrm{ha}^{-1}\right)$ and, in the subplots, the cultivars EMBRAPA 22 and EMBRAPA 42. Soil-water tension of $60 \mathrm{kPa}$ was more adequate for management of irrigation in wheat, since it did not affect its grain yield and quality and used less water. The dose of nitrogen that promoted maximum technical efficiency was $73 \mathrm{~kg} \mathrm{ha}^{-1}$. The crude protein content increased as nitrogen increased. The increase of irrigation frequency and nitrogen decreased the hectolitergrain weight.
\end{abstract}

Key words: Triticum aestivum, no-tillage, nitrogen fertilization, soil-water tension 


\section{INTRODUÇÃO}

O suprimento adequado de nutrientes em sistemas de cultivo de trigo pode ser alcançado por meio de duas estratégias: da adoção de práticas culturais mais eficientes ou da obtenção de cultivares mais responsivas na captação e utilização do nutriente (Ortiz-Monasterio et al., 2001). No Brasil, dá-se muita atenção à primeira estratégia, sobretudo nas regiões consideradas produtoras tradicionais, porém, nas fronteiras agrícolas a triticultura demanda a geração de conhecimentos e tecnologias aplicadas para a solução de problemas regionais.

No Cerrado brasileiro, a área cultivada com trigo aumentou consideravelmente nos últimos anos, tendo em vista o desenvolvimento de cultivares especificamente para essas condições edafoclimáticas; nessas áreas, no entanto, o manejo da cultura permanece como fator limitante para o incremento e estabilização da produtividade. Estudos avaliando adubação nitrogenada e irrigação (Caviglia \& Sadras, 2001; Zagonel et al., 2002; Li \& Rao, 2003) são imprescindíveis para atualizar as recomendações técnicas e disponibilizar tecnologias que proporcionem produções economicamente satisfatórias. Nesses trabalhos, constatou-se que a resposta das cultivares de trigo a irrigação e fertilização, é caraterizada pela relação positiva entre tais fatores. A natureza desta interação, entretanto, é função das condições edafoclimáticas, cultivares e técnicas de manejo empregadas (Frizzone et al., 1996; Sandhu et al., 2002; Readman et al., 2002). A eficiência e/ou resposta dos genótipos de trigo a doses de nitrogênio em relação à produtividade, depende da disponibilidade de água. A deficiência hídrica no solo limita a resposta da planta à aplicação de fertilizantes, retardando os processos envolvidos na nutrição mineral: difusão, fluxo de massa e interceptação pelas raízes. O trigo é uma cultura que responde bem ao incremento tecnológico na quantidade de água aplicada durante o ciclo. As produtividades médias das culturas irrigadas chegam a ser três vezes maiores que das culturas de sequeiro. Embora se trate de uma cultura mais resistente ao déficit hídrico que muitas outras, alguns estádios de desenvolvimento são bastante afetados pelo estresse hídrico (Acevedo et al., 2002).

A nutrição mineral tem efeito na produtividade, sendo o nitrogênio o nutriente quantitativamente mais importante e o de maior impacto (Lamothe, 1998; Sylvester-Bradley et al. 2001). A deficiência de nitrogênio pode reduzir a evapotranspiração e a eficiência do uso da água na cultura do trigo
(Nielsen \& Halvorson, 1991) e, também, afetar a interceptação da radiação, diminuindo a eficiência do uso da radiação (Abbate et al., 1995).

Todos os componentes do rendimento do trigo podem beneficiar-se em maior ou menor grau do nitrogênio, exceto a população de plantas (Zagonel et al., 2002). Desta forma, uma quantidade adequada de nitrogênio é essencial para incrementar a produtividade. O nitrogênio pode incrementar o número de espiguetas por espiga, de grãos por espigueta e o tamanho do grão, ainda que seu efeito sobre este último componente seja pouco consistente, pois é dependente das condições ambientais durante a sua formação. Embora se possa incrementar cada um dos componentes, individualmente, fenômenos compensatórios fazem com que, freqüentemente, os componentes se relacionem de forma negativa, tendendo a propiciar o incremento de uns e o decréscimo de outros; assim, a mesma produtividade pode ser obtida por diferentes caminhos, sendo difícil estabelecer-se uma combinação ótima dos componentes (Lamothe, 1998).

A influência de crescentes doses de nitrogênio sobre os componentes da produtividade de uma cultura deve ser estudada em condições específicas de ambiente pelo fato desses componentes receberem influência dos diversos fatores climáticos. Objetivou-se, através deste trabalho, avaliar os efeitos de doses de nitrogênio em cobertura, sob dois manejos de irrigação, na produtividade de duas cultivares de trigo e seus componentes, na região do cerrado.

\section{MATERIAL E MÉTODOS}

Conduziram-se dois experimentos com a cultura do trigo irrigado na Embrapa Arroz e Feijão, localizada no município de Santo Antônio de Goiás, GO, latitude $16^{\circ} 28^{\prime} \mathrm{S}$, longitude $49^{\circ} 17^{\prime}$ e altitude de $824 \mathrm{~m}$. O solo da área experimental é classificado como Latossolo Vermelho distrófico, de textura argilosa. Os resultados da análise química do solo, obtidos antes do início dos experimentos, estão apresentados na Tabela 1.

Em um dos experimentos, a irrigação foi conduzida de maneira que o seu reinício se desse quando uma bateria de tensiômetros instalada a $0,15 \mathrm{~m}$ de profundidade acusava a tensão matricial de $40 \mathrm{kPa}$; no outro experimento, o reinício da irrigação ocorria na tensão matricial de $60 \mathrm{kPa}$. Utilizou-se o sistema convencional de irrigação por

Tabela 1. Resultados da análise química do Latossolo Vermelho distrófico da área experimental

\begin{tabular}{|c|c|c|c|c|c|c|c|c|c|c|c|c|}
\hline \multirow{2}{*}{$\begin{array}{c}\text { Camada } \\
\text { (cm) }\end{array}$} & \multirow{2}{*}{ pH água } & $\mathrm{Ca}$ & $\mathrm{Mg}$ & Al & $\mathrm{H}+\mathrm{Al}$ & $P$ & K & $\mathrm{Cu}$ & $\mathrm{Zn}$ & $\mathrm{Fe}$ & $\mathrm{Mn}$ & \multirow{2}{*}{$\begin{array}{l}\text { M.O. } \\
\text { g dm-3 }\end{array}$} \\
\hline & & \multicolumn{4}{|c|}{$\mathrm{mmol}_{\mathrm{c}} \mathrm{dm}^{-3}$} & \multicolumn{6}{|c|}{$\mathrm{mg} \mathrm{dm^{-3 }}$} & \\
\hline $0-10$ & 6,5 & 40,5 & 15,4 & 0 & 38 & 7,2 & 161 & 5,0 & 1,7 & 45 & 57 & 16 \\
\hline $10-20$ & 6,1 & 26,1 & 9,6 & 0 & 40 & 4,3 & 81 & 5,3 & 1,4 & 38 & 39 & 14 \\
\hline $20-40$ & 5,3 & 8,1 & 3,3 & 2 & 56 & 0,9 & 75 & 4,7 & 0,8 & 49 & 25 & 12 \\
\hline $40-60$ & 5,5 & 11,7 & 4,0 & 1 & 33 & 0,4 & 53 & 4,1 & 0,3 & 44 & 20 & 10 \\
\hline $60-80$ & 5,7 & 9,0 & 3,2 & 0 & 24 & 0,1 & 34 & 3,8 & 0,3 & 38 & 14 & 6 \\
\hline
\end{tabular}


aspersão, cujos aspersores eram da marca Perrot, tipo 2ED30, com diâmetro de bocal de 6,0 x 9,5 mm, pressão de serviço de $4 \mathrm{~atm}$, com intensidade de aplicação de $16,48 \mathrm{~mm} \mathrm{~h}^{-1}$ no espaçamento de 24 x $24 \mathrm{~m}$. Para determinação da umidade do solo e, conseqüentemente, do armazenamento de água no perfil, empregou-se sonda de nêutrons manufaturada pela Campbell Pacific Nuclear, modelo CPN 503. O perfil do solo foi monitorado em camadas de 10 a $40 \mathrm{~cm}$ de profundidade duas vezes por semana. Em ambos os experimentos, o delineamento experimental foi o de blocos ao acaso, com parcelas subdivididas e quatro repetições, em que nas parcelas se estabeleceram cinco doses de nitrogênio em cobertura, 0, 50, 100, 150 e $200 \mathrm{~kg} \mathrm{ha}^{-1}$ e, nas subparcelas, duas cultivares de trigo, EMBRAPA 22 e EMBRAPA 42. A área das subparcelas foi de $6 \mathrm{~m}^{2}$, utilizadas para determinação da produtividade apenas as três linhas centrais, com área útil de $3 \mathrm{~m}^{2}$.

A semeadura foi realizada em 16/5/2003, através do sistema plantio direto; a cultura anterior foi soja, que deixou uma quantidade de resíduo de $1857 \mathrm{~kg} \mathrm{ha}^{-1}$ para a área do experimento 1 (irrigação quando a tensão no solo atingir $40 \mathrm{kPa}$ ) e $2943 \mathrm{~kg} \mathrm{ha}^{-1}$ para a área do experimento 2 (irrigação quando a tensão no solo atingir $60 \mathrm{kPa}$ ). A densidade de semeadura foi de 350 sementes aptas por $\mathrm{m}^{2}$, com espaçamento de 0,20 m entrelinhas. Aplicaram-se 10 t de calcário dolomítico antes da semeadura e $400 \mathrm{~kg} \mathrm{ha}^{-1}$ da fórmula 4-30-16 na adubação de semeadura. A adubação de cobertura foi realizada aplicando-se uréia, a lanço, em duas etapas: no início do estádio de perfilhamento, 15 dias após a emergência do trigo, e a 30 dias após a emergência, conforme os tratamentos adotados. Mediu-se o teor de $\mathrm{N}$ nos grãos pelo método semimicrokjeldahl (Tedesco et al., 1995). Os valores encontrados foram multiplicados por 5,83, que é o valor de conversão para obtenção do teor de proteína bruta, em grãos inteiros de trigo.

As variáveis analisadas foram: número de grãos por $\mathrm{m}^{2}$, massa de mil grãos, produtividade, peso hectolítrico e teor de proteína bruta. Fez-se a análise conjunta dos dois experimentos e, para as análises de variância e de regressão, utilizou-se o software SAS 8.2.

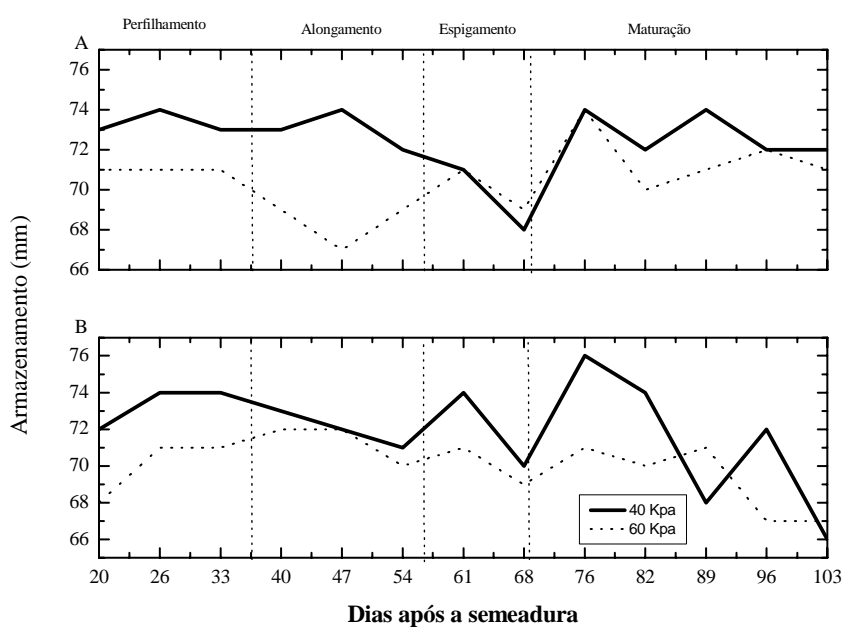

Figura 1. Armazenamento de água no solo nas camadas de $0-0,20 \mathrm{~m}$ (a) e 0,20-0,40 m (b), durante o período dos experimentos, afetado pelo manejo da irrigação

\section{RESULTADOS E DISCUSSÃO}

Durante o período total de duração do ensaio foram aplicados 477,2 e 424,5 mm de água para a irrigação reiniciada, respectivamente, na tensão matricial de 40 e $60 \mathrm{kPa}$. As lâminas de água foram medidas por meio de pluviômetros instalados na área experimental. Guerra et al. (1994) também observaram decréscimo na quantidade de água aplicada com o aumento da tensão de água no solo. A irrigação mais freqüente, reinício a $40 \mathrm{kPa}$, proporcionou maior armazenamento de água nas camadas de solo de 0-0,20 e 0,20-0,40 m (Figura 1); apesar disto, o manejo da irrigação não afetou as variáveis estudadas, com exceção do peso hectolítrico (Tabela 2). Guerra et al. (1994) também não constataram diferenças significativas na produtividade do trigo nem na massa de 1000 grãos na faixa de tensão de água no solo de 37 a $67 \mathrm{kPa}$.

$\mathrm{O}$ número de grãos por $\mathrm{m}^{2}$ foi influenciado significativamente pelas cultivares e doses de nitrogênio, enquanto a massa de mil grãos o foi somente pela cultivar (Tabela 2).

Tabela 2. Resumo das análises de variância da produtividade de trigo irrigado e seus componentes, sob sistema de plantio direto, após a soja

\begin{tabular}{|c|c|c|c|c|c|c|}
\hline \multirow[b]{2}{*}{ Fonte de variação } & \multirow[b]{2}{*}{ G.L. } & \multicolumn{5}{|c|}{ Quadrado Médio } \\
\hline & & $\begin{array}{l}\text { Grãos } \\
\left(\mathrm{n}^{0} \mathrm{~m}^{-2}\right)\end{array}$ & $\begin{array}{l}\text { Massa de } 1000 \text { grãos } \\
\text { (g) }\end{array}$ & $\begin{array}{l}\text { Produtividade } \\
\left(\mathrm{kg} \mathrm{ha}^{-1}\right)\end{array}$ & $\begin{array}{l}\text { Peso hectolítrico } \\
\left(\mathrm{kg} \mathrm{hL}^{-1}\right)\end{array}$ & $\begin{array}{c}\text { Proteína bruta } \\
\text { (\%) }\end{array}$ \\
\hline Experimento (E) & 1 & $3139250^{\text {ns }}$ & $13,098^{\mathrm{ns}}$ & $115698^{\text {ns }}$ & $21,788^{\star \star}$ & $8,582^{\mathrm{ns}}$ \\
\hline Bloco d. E & 6 & 2661944 ns & $2,533^{\mathrm{ns}}$ & 558146 ns & $1,890^{\star}$ & 3,258 ns \\
\hline Nitrogênio (N) & 4 & $60692617^{\star \star \star}$ & 2,516 ns & $10555463 * *$ & 6,520 ** & $119,557^{\star \star \star}$ \\
\hline $\mathrm{E} \times \mathrm{N}$ & 4 & $3022922^{\text {ns }}$ & $2,602^{\text {ns }}$ & $533350^{\text {ns }}$ & $0,527 \mathrm{~ns}$ & 2,288 ns \\
\hline Erro a & 24 & 6717450 & 4,455 & 1627560 & 1,144 & 9,043 \\
\hline Cultivar (C) & 1 & 63801397 ** & 305,176 ** & $957110^{\mathrm{ns}}$ & $12,176^{\star \star}$ & $4,009^{\text {ns }}$ \\
\hline $\mathrm{N} \times \mathrm{C}$ & 4 & $912483^{\text {ns }}$ & $2,153^{\text {ns }}$ & $448417^{\text {ns }}$ & $0,286^{\mathrm{ns}}$ & 3,767 ns \\
\hline $\mathrm{E} \times \mathrm{C}$ & 1 & $1585247^{\mathrm{ns}}$ & 0,170 ns & $438121^{\text {ns }}$ & $1,809 \mathrm{~ns}$ & $2,107^{\text {ns }}$ \\
\hline$E \times N \times C$ & 4 & $896483^{\text {ns }}$ & $1,870^{\text {ns }}$ & $227551^{\text {ns }}$ & 0,544 ns & 1,472 \\
\hline Erro b & 30 & 1927897 & 1,254 & 351228 & 0,640 & 2,015 \\
\hline
\end{tabular}

ns, *, ** - Não significativo e significativo a $5 \%$ e $1 \%$ de probabilidade pelo teste $F$ 
O número de grãos por $\mathrm{m}^{2}$ apresentou resposta quadrática às doses de nitrogênio (Figura 2), sendo o máximo obtido com a dose de 185,9 $\mathrm{kg} \mathrm{ha}^{-1}$ de N. Frizzone et al. (1996) constataram que o incremento na dose de nitrogênio aplicada reduziu o abortamento de perfilhos e aumentou não só o número de grãos por espiga, mas também, o número de grãos por unidade de área. Os autores verificaram, ainda, que o suprimento de nitrogênio pouco contribuiu para o aumento da massa dos grãos. A cultivar EMBRAPA 22 apresentou maior quantidade média de grãos por área, 14367 grãos m²-2, em relação à cultivar EMBRAPA 42, que foi de 12582 grãos $\mathrm{m}^{-2}$, mas esta última cultivar indicou maior massa de mil grãos, 44,34 g, em relação à EMBRAPA 22, que foi de 40,44 g, diferenças essas inerentes às características genéticas das cultivares. $\mathrm{O}$ maior número de grãos por $\mathrm{m}^{2}$ da cultivar EMBRAPA 22 se deve ao seu maior número de espiguetas por espiga, uma vez que o número de grãos por espigueta e o índice de perfilhamento são semelhantes aos da 'EMBRAPA 42' (Reis et al., 1999).

A produtividade do trigo foi afetada, significativamente apenas pelas doses de nitrogênio (Tabela 2), apresentando resposta quadrática ao aumento das doses aplicadas em cobertura (Figura 2B), devido ao efeito deste nutriente no número de grãos por $\mathrm{m}^{2}$.

A produtividade em $\mathrm{kg} \mathrm{ha}^{-1}$ apresentou correlação significativa com o número de grãos $\mathrm{m}^{-2}$, expressa pela equação $\mathrm{Y}=845,24+0,361 \mathrm{X}, \mathrm{R}=0,94 * *$. Segundo Mallmann et al. (1994), o número de grãos por $\mathrm{m}^{2}$ quase sempre exerce maior influência na produtividade, que a massa do grão. A produtividade máxima estimada foi de $6370 \mathrm{~kg} \mathrm{ha}^{-1}$, obtida com a dose de 172,9 $\mathrm{kg} \mathrm{ha}^{-1}$ de $\mathrm{N}$. Considerando-se $90 \%$ da produtividade máxima, $5733 \mathrm{~kg} \mathrm{ha}^{-1}$, como a máxima eficiência técnica (Fageria et al., 1997), a dose econômica de nitrogênio seria de $73 \mathrm{~kg} \mathrm{ha}^{-1}$, cujo valor é superior ao recomendado para o Brasil Central, ou seja de $60 \mathrm{~kg} \mathrm{ha}^{-1}$ (CCBPT, 2003); entretanto, este tipo de comparação deve ser feito com ressalvas pois é dependente do ambiente e da cultivar empregada; referidos resultados indicam, ainda, que existem restrições à utilização de recomendações generalizadas para aplicação de nitrogênio em cobertura.

Utilizando em experimentos diferentes cultivares de trigo, diversos autores (Sandhu et al., 2002; Frizzone et al., 1996), observaram resposta positiva a doses de nitrogênio, mas em alguns estudos realizados no Cerrado com o trigo sucedendo a soja, não se encontraram efeitos significativos do nitrogênio na produtividade (Silva, 1991), em virtude da contribuição da soja no suprimento de nitrogênio do solo. No presente trabalho, o nitrogênio residual da cultura da soja não foi suficiente para incrementar a produtividade de trigo. A não aplicação de nitrogênio em cobertura, resultou em 22,6\% de redução na produtividade, em relação à dose econômica de nitrogênio.

O peso hectolítrico foi afetado significativamente pelo manejo da irrigação, dose de nitrogênio e cultivar (Tabela 2); esta variável é importante, pois serve como parâmetro para a comercialização de grãos, uma vez que, na prática, o valor recebido pelo produtor é menor quando o peso hectolítrico se apresenta abaixo de $78 \mathrm{~kg} \mathrm{hL}^{-1}$. A irrigação mais freqüente, reinício na

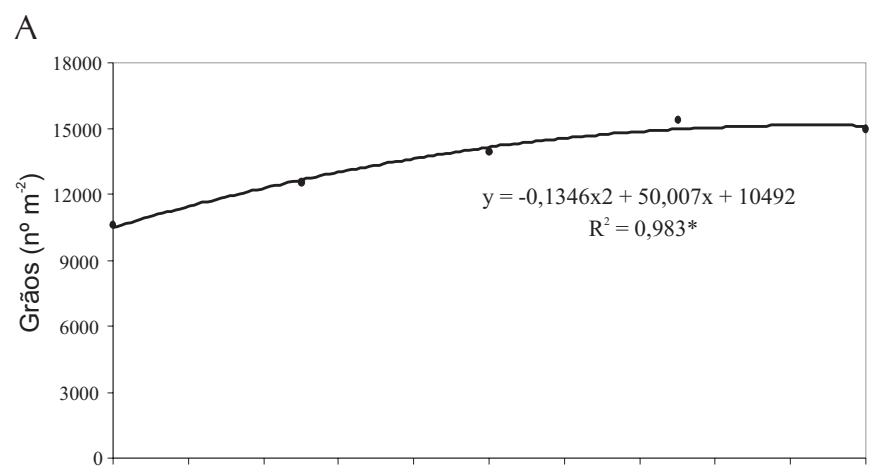

B

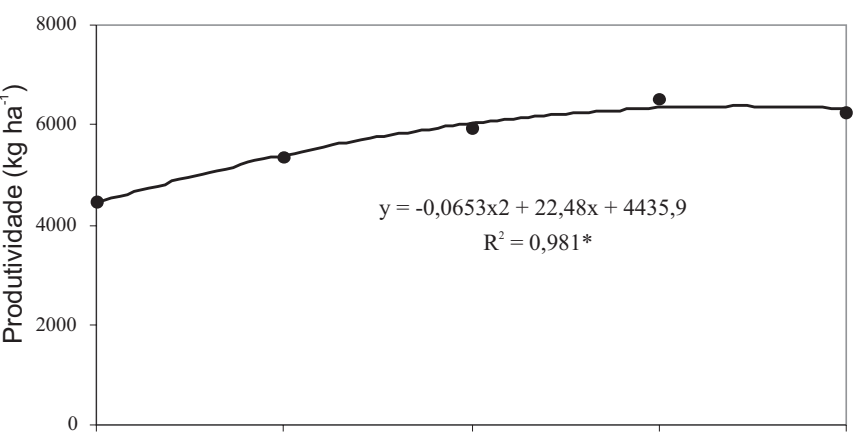

C

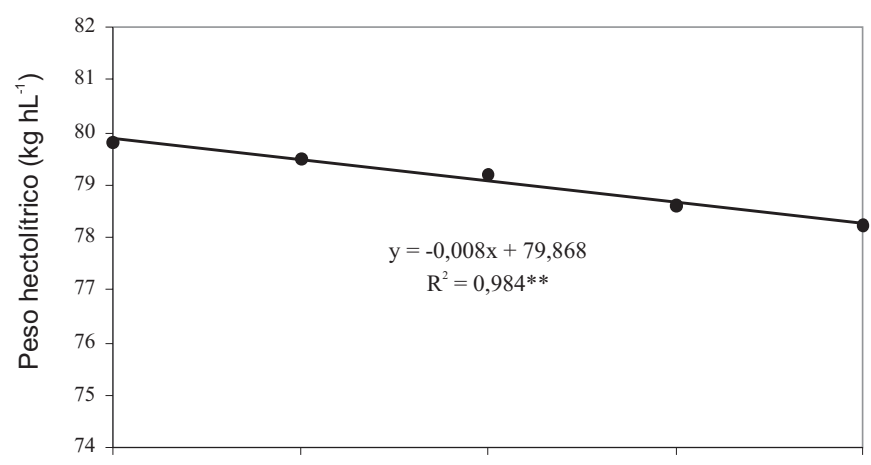

D

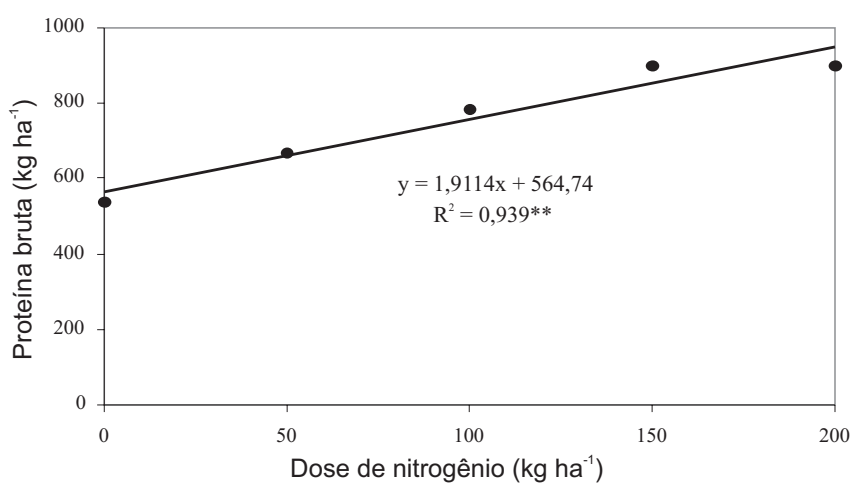

Figura 2. Número médio de grãos de trigo por $\mathrm{m}^{2}$ (A), Produtividade média do trigo (B), Peso hectolítrico médio do trigo (C), Teor médio de proteína bruta dos grãos de trigo (D), em função de doses de nitrogênio aplicadas em cobertura. Santo Antônio de Goiás, 2003 
tensão de $40 \mathrm{kPa}$, propiciou menor valor médio do peso hectolítrico, 78,5 kg hL-1, em relação ao reinício na tensão de $60 \mathrm{kPa}$, que foi de 79,6 $\mathrm{kg} \mathrm{hL}^{-1}$. Guerra et al. (1994) não notaram efeito do manejo da irrigação sobre esta variável, porém Frizzone et al. (1996) verificaram que tanto o excesso como o déficit de irrigação diminuíram o peso hectolítrico. A cultivar EMBRAPA 22 apresentou menor peso hectolítrico, 78,7 $\mathrm{kg} \mathrm{hL}^{-1}$, que a EMBRAPA 42, em que este valor foi $79,4 \mathrm{~kg} \mathrm{hL}^{-1}$. Reis et al. (1999), entretanto, não notaram diferença significativa entre essas duas cultivares, quanto ao peso hectolítrico. O peso hectolítrico diminuiu linearmente com o aumento das doses de nitrogênio (Figura 2C), embora tenha ficado sempre acima do limite de $78 \mathrm{~kg} \mathrm{hL}^{-1}$. Frizzone et al. (1996) ainda observaram redução no peso hectolítrico com o aumento da adubação nitrogenada, em que a razão pode ser atribuída à maior competição entre os grãos por fotoassimilados, uma vez que o aumento da dose de nitrogênio aumentou o número de grãos por unidade de área. De fato, a massa dos grãos apresentou correlação negativa com o número de grãos por $\mathrm{m}^{2}$, com $\mathrm{R}=-0,44^{*}$. Segundo Mallmann et al. (1994), grãos menores proporcionam seu melhor ajuste no cilindro da balança, evitando espaços vazios e provocando maior aglutinação dos grãos no momento de aferição do peso hectolítrico.

O teor de proteína bruta do grão foi influenciado significativamente apenas pelas doses de nitrogênio (Tabela 2); este aspecto da qualidade do trigo, embora ainda não considerado no momento da sua comercialização no Brasil, é de interesse relevante para os consumidores. Esta variável apresentou resposta linear crescente às doses de nitrogênio (Figura 2D). O teor de proteína do grão é afetado, sobretudo, pelo local de plantio, condições climáticas durante a fase de maturação do grão, práticas culturais, doenças, pragas e pelo genótipo (Guarienti, 1996). Neste estudo, entretanto, não houve diferença entre as cultivares, quanto ao teor de proteína.

\section{CONCLUSÕES}

1. A tensão matricial de $60 \mathrm{kPa}$ foi mais adequada para o manejo da irrigação no trigo, pois não afetou sua produtividade nem a qualidade, mas utilizou menor lâmina total de água.

2. A dose econômica de nitrogênio em cobertura para o trigo irrigado, cultivado em sucessão à soja, foi de $73 \mathrm{~kg} \mathrm{ha}^{-1}$.

3. O teor de proteína bruta aumentou linearmente com o incremento da dose de nitrogênio em cobertura.

4. O incremento da freqüência de irrigação e da dose de nitrogênio em cobertura, diminuiu o peso hectolítrico.

\section{LITERATURA CITADA}

Abbate, P. E.; Andrade, F. H.; Culot, J. F. The effects of radiation and nitrogen on number of grains in wheat. Journal of Agricultural Science, Cambridge, v.124, n.3, p.351-360, 1995.

Acevedo, E.; Silva, P.; Silva, H. Wheat growth and physiology. In: Curtis, B. C.; Rajara, S.; Macpherson, H. G. (eds.). Bred Wheat - improvement and production. Rome: FAO. p. 39-70, 2002.
Caviglia, O. P.; Sadras, V. O. Effect of nitrogen supply on crop conductance, water and radiation-use efficiency of wheat. Field Crops Research, Amsterdam, v.69, p.259-266, 2001.

CCBPT - Comissão Centro Brasileira de Pesquisa de Trigo, 12, 2002, Uberlândia. Indicações técnicas para a cultura de trigo na Região do Brasil Central safra 2003 e 2004. Passo Fundo: Embrapa Trigo-Embrapa Transferência de Tecnologia-Escritório de Negócios do Triângulo Mineiro, 2003. 109p. Reunião da Comissão Centro Brasileira de Pesquisa de Trigo.

Fageria, N. K.; Baligar, V. C.; Jones, C. A. Growth and mineral nutrition of field crops. 2.ed. Revised and expanded. New York: Marcel Dekker, Inc. 1997. 624p.

Frizzone, J. A.; Mello Júnior, A. V.; Folegatti, M. V.; Botrel, T. A. Efeito de diferentes níveis de irrigação e adubação nitrogenada sobre componentes de produtividade da cultura do trigo. Pesquisa Agropecuária Brasileira, Brasília, v.31, n.6, p.425434, 1996.

Guarienti, E. M. Qualidade industrial de trigo. 2.ed. Passo Fundo: Embrapa-CNPT, 1996. 36p. Documentos, 27

Guerra, A. F.; Silva, E. M. da; Azevedo, J. A. de. Tensão de água no solo: um critério viável para a irrigação do trigo na região do Cerrado. Pesquisa Agropecuária Brasileira, Brasília, v.29, n.4, p.631-636, 1994.

Lamothe, A. G. Fertilización con N y potencial de rendimiento en trigo. In: Kohli, M. M.; Martino, D. L. (ed.). Explorando altos rendimientos de trigo. Montevideo: CIMMYT/INIA, 1998. p.207-246.

Li, J.; Rao, M. Field evaluation of crop yield as affected by nonuniformity of sprinkler-applied water and fertilizers. Agricultural Water Management, Amsterdam, v.59, p.1-13, 2003.

Mallmann, I. L.; Barbosa Neto, J. F.; Carvalho, F. I. F. de; Federizzi, L. C. Mecanismos de seleção aplicados sobre o caráter tamanho de grãos em populações segregantes de trigo. Pesquisa Agropecuária Brasileira, Brasília, v.29, n.3, p.427437, 1994.

Nielsen, D. C.; Halvorson, A. D. Nitrogen fertility influence on water stress and yield of winter wheat. Agronomy Journal, Madison, v.83, n.6, p.1065-1070, 1991.

Ortiz-Monasterio, J. I.; Manske, G. G. B.; Van Ginkel, M. Nitrogen and phosphorus use efficiency. In: Reynolds, M. P.; Ortiz-Monasterio, J. I.; McNab, A. (eds.). Application of physiology in wheat breeding. Mexico: CIMMYT, 2001. p.200-207.

Readman, R. J.; Kettlewell, P. S.; Beckwith, C. P. Effects of spray application of urea fertilizer at stem extension on winter wheat yield. Journal of Agricultural Science, Cambridge, v.139, n.1, p.1-10, 2002.

Reis, W. P.; Vello, N. A.; Ferreira, D. F.; Ramalho, M. A. P. Associação entre coeficiente de parentesco e técnicas multivariadas como medidas de divergência genética de cultivares de trigo. Ciência e Agrotecnologia, Lavras, v.23, n.2, p.258269, 1999.

Sandhu, K. S.; Arora, V. K.; Chand, R. Magnitude and economics of fertilizer nitrogen response of wheat in relations to amount and timing of water inputs. Experimental Agriculture, London, v.38, n.1, p.65-78, 2002. 
Silva, D. B. Efeito do nitrogênio em cobertura sobre o trigo irrigado em sucessão à soja na região dos Cerrados. Pesquisa Agropecuária Brasileira, Brasília, v.26, n.9, p.1387-1392, 1991.

Sylvester-Bradley, R.; Stokes, D. T.; Scott, R. K. Dynamics of nitrogen capture without fertilizer: the baseline for fertilizing winter wheat in the UK. Journal of Agricultural Science, Cambridge, v.136, p.15-33, 2001.
Tedesco, M. J.; Gianello, C.; Bissani, C. A.; Bohnen, H.; Volkweiss, S. J. Análises de solo, plantas e de outros materiais. Porto Alegre: UFRGS-Departamento de Solos, 1995. 174p. Boletim Técnico, 5

Zagonel J.; Venâncio, W. S.; Kunz, R. P.; Tanamati, H. Doses de nitrogênio e densidades de plantas com e sem regulador de crescimento afetando o trigo, Cultivar OR-1. Ciência Rural, Santa Maria, v.32, n.1, p.25-29, 2002. 